\title{
Treatment of palm oil mill effluent using biological sequencing batch reactor system
}

\author{
C. W. Fun, M. R. U. Haq \& S. R. M. Kutty \\ Department of Civil Engineering, Universiti Teknologi PETRONAS, \\ Malaysia
}

\begin{abstract}
Palm Oil Mill Effluent (POME) is known to cause serious environmental hazards due to its high biochemical (BOD) and chemical oxygen demand (COD) if disposed without proper treatment. Moreover, the processing of palm fruit causes POME to have fibre and husk resulting in high level of total suspended solids (TSS) and turbidity. This work focused to further treat effluent from the anaerobic pond of a nearby palm oil mill using biological sequencing batch reactor (SBR) system. The biological treatment was conducted in six phases using the SBR system where phase 1 had 10 days sludge age and 30 minutes settling time. Phase 2 had the same conditions as phase 1 with increased mixed liquor suspended solids (MLSS). In phase 3, the MLSS was maintained at $2500-4000 \mathrm{mg} / \mathrm{l}$ with a settling time of 45 to 60 minutes. In Phase 4 , the aeration time was at four days with settling time of 60 to 75 minutes while phase 5 had three days aeration and one day idle time. In Phase 6, the aeration time was increased to six days with 60 to 75 minutes settling time. The highest removals were achieved from Phase 5 with percentage removals of $62 \%$ for TSS, $82 \%$ for total COD and $88 \%$ for soluble COD.
\end{abstract}

Keywords: POME, mixed liquor suspended solids (MLSS), TSS, sequencing batch reactor $(S B R)$.

\section{Introduction}

In Malaysia, palm oil is very productive where palm oil mills are operated at least 300 days per year. After processing the fresh fruit bunch (FFB), $78 \%$ are removed as waste such as empty fruit bunches shell, fibre and liquid effluent. Generally, the effluent from palm oil mill is acidic in nature and has high BOD 
and COD. By 1970s, 42 rivers in Malaysia were severely aerobically polluted by effluent from palm oil mills (Zulkifli [1]). A survey conducted by PORIM and the Rubber Research Institute of Malaysia in 1980-81 that $90 \%$ of the mills surveyed discharges POME with a BOD concentration below the standard at that time $(500 \mathrm{mg} / \mathrm{l})$, and that $40 \%$ were discharging POME with a BOD concentration below $100 \mathrm{mg} / \mathrm{l}$. However, the survey also reveals that standards on COD, total solids and organic nitrogen have been proven difficult to achieve by industries. In concession to this, the Department of Environment (DOE) eliminated the standards on COD, total solids, and organic nitrogen while the BOD standard has been lowered to $250 \mathrm{mg} / \mathrm{l}$ (Khalid [2]). Due to the eliminations of these parameters, by the end of $1982,80 \%$ of the palm oil mills complied with the standard. However, this new standard no longer has the limit for COD and total solids. As for turbidity, so far there has not been a limit on it for the palm oil industry. Thus, this study was conducted to evaluate the COD, TSS and turbidity removal by biological treatment using SBR method to test for the further removal of total and soluble COD as well as TSS.

Several innovative treatment technologies have been developed and applied by palm oil mills to treat POME since the enactment of the Environment Quality Act, 1974. The most commonly used treatment is the conventional biological treatments of anaerobic or facultative digestion treatment. As POME has high organic content, it is easy to be biodegradable and essentially three well-known processes for POME treatment are anaerobic, aerobic and facultative process while the commonly system used by palm oil industry is the ponding system (Ahmad et al. [3]). Anaerobic treatment system requires regular desludging, as sludge accumulation will cause the pond volume to reduce with subsequent reduction in pond retention time and reduce overall treatment efficiency (GTZ [4]). The most widely use aerobic treatment system is the aerobic pond system which needs electrical power for aeration. Thus, this system requires much less surface area and shorter retention time compared to other ponds. The activated sludge system is one of the most effective aerobic treatment systems but is the least used by palm oil mill that may be caused by the cost operation of the pond systems compared to the activated sludge system. The operation units of this system are aeration tank, sedimentation tank, and return sludge pumping system and excess sludge removal and treatment (Thanh [5]).

SBR is a fill-and-draw activated sludge system for wastewater treatment where wastewater is added to a single "batch" reactor treated to remove undesirable components and then discharged. Equalization, aeration, and clarification can all be achieved in a single batched reactor. SBR systems have been successfully used to treat both municipal and industrial wastewater as they are suited for wastewater treatment applications characterized by low or intermitted flow conditions (Dea and Jong [6]).

All samples for this study were taken from a near by palm oil mill in Perak and results were based on samples taken from that mill. The effectiveness of SBR treatment is based on TSS, total COD (TCOD) and soluble COD (SCOD). The effluent treatment system needs to be efficient, rapid and should be simple to be attractive cost-wise. 


\section{Methodology}

\subsection{Sampling}

Fifty litres of POME were taken from the mill's anaerobic pond to be treated using the SBR bench scale system. Five litres of water sample and sludge were also taken from the aeration pond as seed for the SBR system. Additional five litres of wastewater sludge was taken from a near by sewerage treatment system as additional seed for the SBR system.

\subsection{Experimental procedures}

A fill-and-draw SBR system with a ten litres working volume was operated as shown in Figure 1. Basically, the system involved filling the system with influent, aeration, settling or idle period and decanting before refilling again. The influent parameters monitored were TSS, TCOD and SCOD before it was filled in the SBR system.

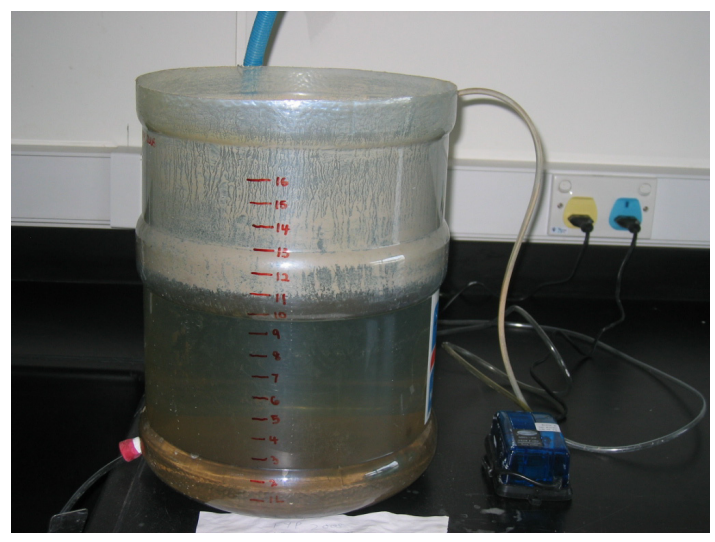

Figure 1: Bench scale SBR system used in experiments.

During the testing period, one litre of sample from the SBR system was taken out to determine the value of sludge volume index (SVI) of the MLSS. This was done by dividing the volume of sludge settled in one litre with the MLSS. After that, the decanted sample was tested for TSS, TCOD and SCOD. The results were then compared with the influent results to obtain the percentage removals of the parameters. The cycle time in terms of the aeration period, settlement time, idle period, decant volume and sludge age were varied in six phases to determine the optimum conditions. The six different phases for the SBR experimental process in this study that had been summarized in Table 1 . 
Table 1: $\quad$ Conditions in SBR.

\begin{tabular}{|l|c|c|c|c|c|c|}
\hline \multicolumn{1}{|c|}{ Phase } & $\mathbf{1}$ & $\mathbf{2}$ & $\mathbf{3}$ & $\mathbf{4}$ & $\mathbf{5}$ & $\mathbf{6}$ \\
\hline $\begin{array}{l}\text { Cycle Time, } \\
\text { days }\end{array}$ & $1-2$ & $1-2$ & $1-3$ & 4 & 4 & 6 \\
\hline $\begin{array}{l}\text { Sludge Age, } \\
\text { days }\end{array}$ & 10 & 10 & - & - & - & - \\
\hline MLSS, mg/1 & - & $\sim 4000$ & $\begin{array}{c}2500- \\
4000\end{array}$ & $\begin{array}{c}2500- \\
4000\end{array}$ & $\begin{array}{c}2500- \\
4000\end{array}$ & $\begin{array}{c}2500- \\
4000\end{array}$ \\
\hline $\begin{array}{l}\text { Aeration, } \\
\text { days }\end{array}$ & $1-2$ & $1-2$ & $1-3$ & 4 & 3 & 6 \\
\hline Idle, days & None & None & None & None & 1 & None \\
\hline Settling, min & 30 & 30 & $45-60$ & $60-75$ & None & $60-75$ \\
\hline Decant & $\begin{array}{c}1 \\
\text { lit/day }\end{array}$ & $\begin{array}{c}1 \\
\text { lit/day }\end{array}$ & $\begin{array}{c}4 \\
\text { lit/cycle }\end{array}$ & $\begin{array}{c}4 \\
\text { lit/cycle }\end{array}$ & $\begin{array}{c}4 \\
\text { lit/cycle }\end{array}$ & $\begin{array}{c}4 \\
\text { lit/cycle }\end{array}$ \\
\hline
\end{tabular}

\section{Results and discussion}

\subsection{MLSS and TSS results in SBR}

For industrial wastewater such as POME treatment system, the ideal value of MLSS is from $2500 \mathrm{mg} / 1$ to $4000 \mathrm{mg} / \mathrm{l}$ (EPA). Figure 2 showed the MLSS trend in the SBR system throughout the experiment. In phase 1, two litres of MLSS was taken from the mill's treatment system as seed for the SBR system. This is to simulate the actual treatment system of the mill. It was found that MLSS results were found to be less than $1000 \mathrm{mg} / \mathrm{l}$. In phase 2, MLSS was increased to $4000 \mathrm{mg} / \mathrm{l}$ by adding sludge from a nearby sewerage treatment plant (STP) as it was determined that the MLSS was insufficient in Phase 1. In this phase, sludge was wasted at the end of each cycle to maintain a sludge age of 10 days. This reduced the MLSS to approximately $2500 \mathrm{mg} / \mathrm{l}$. In Phase 3, sludge was not wasted and the volume of decant was increased to 4 litres per cycle. With this modification, the MLSS in phase 3 was maintained at approximately $2500 \mathrm{mg} / \mathrm{l}$. For phase 4, 5 and 6, the MLSS was maintained within the range of $2500 \mathrm{mg} / \mathrm{l}$ to $4000 \mathrm{mg} / \mathrm{l}$. Sludge was not wasted from the system unless the MLSS went up to more than $4000 \mathrm{mg} / \mathrm{l}$.

Figure 3 showed the influent TSS (ITSS) and effluent TSS (ETSS) versus time throughout the experiment. In phase 1, the maximum removal of TSS achieved was approximately $23 \%$. The low removal may be due to insufficient MLSS in the system. When the MLSS were increased in phase 2, the ETSS was found to be higher than the ITSS. This may be due to a shorter settling time during prior to decant phase. In Phase 3 the settling period was increased to 45 to 60 minutes. In phase 3 , the $1^{\text {st }}$ and $5^{\text {th }}$ sampling had a settling time of 60 minutes and gave a positive percentage removal. Thus, it was concluded that the settling time should be at least 60 minutes to get positive results in TSS removal. 
Hence, in Phase 4 the settling time was set to be in range of 60 to 75 minutes. A higher percentage removal of TSS was observed in phase 4 . The highest percentage removal of TSS was found to be approximately 54\%. In Phase 5 an idle time of one day was included in the cycle after three days of aeration. During this idle time, the sludge was allowed to settle. Samplings were conducted before and after idle time. TSS removal prior to idle time was about $27 \%$ while TSS removal at the end of the idle time was found to be approximately $62 \%$. In phase 6 , the aeration time was increased to six days with a settling time of 60 to 75 minutes, the percentage TSS removal was found to be approximately $56 \%$. Phase 5 that had an idle time gave better TSS removal.

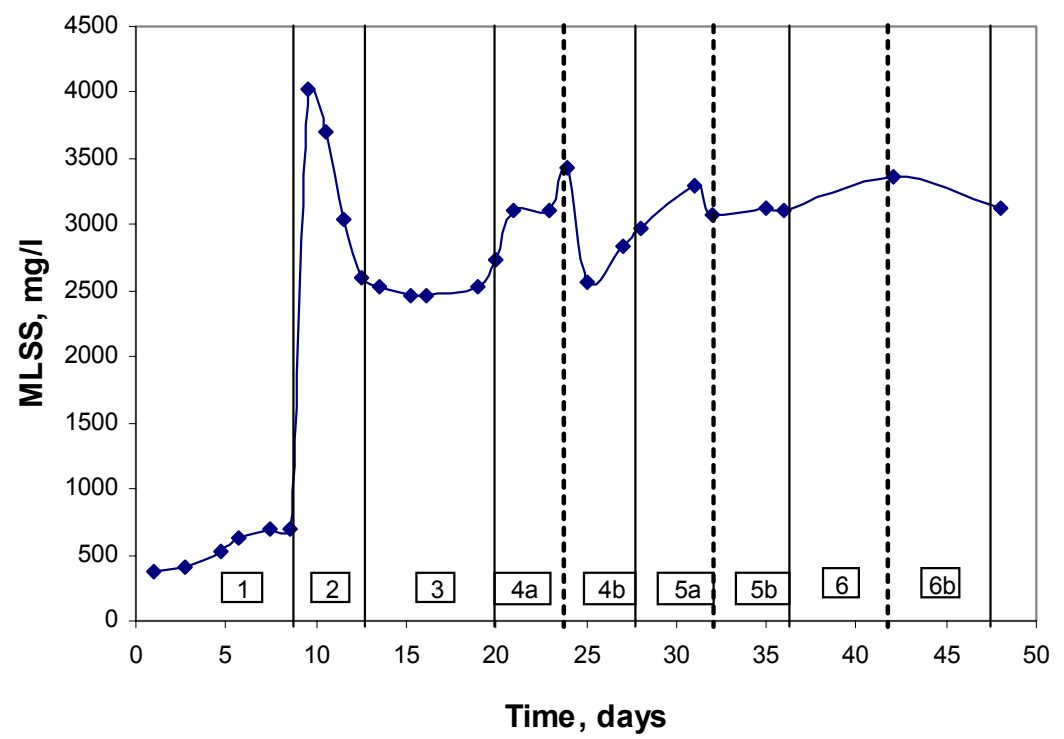

Figure 2: $\quad$ MLSS concentration versus sampling days.

\subsection{Total COD results in SBR}

Figure 4 showed the influent (ITCOD) and effluent (ETCOD) throughout the six phases of the study. In Phase 1, the average TCOD removal obtained was approximately $23 \%$ while the average TCOD removal in Phase 2 was approximately $25 \%$. Towards the end of phase 2 , the percentage TCOD removal was only $15 \%$. This may be caused by the drop in MLSS that was recorded at the end of Phase 2. In Phase 3, the settling time was increased from 30 minutes to a range of 45 to 60 minutes. Better TCOD removal results were obtained from Phase 3 compared to Phases 1 and 2. The settling time may have an impact in improving the results. In this phase, the highest TCOD removal was approximately 54\% removal of TCOD which was recorded on the first sampling point. The first and last sampling points gave better TCOD removals. This may be due to the longer settling time of 60 minutes. In Phase 4 the SBR system had a four days cycle and include four days aeration period. Testing of samples was 
done on the first, third and fourth day of the cycle. Phase 4 was then repeated again in Phase $4 \mathrm{~b}$. It was observed that Phase 4 gave better TCOD removals compared to the previous phases. In this phase, the percentage TCOD removal obtained was approximately 76\%. The TCOD removal in Phase $4 \mathrm{~b}$ was also approximately the same as in Phase $4 \mathrm{a}$. It can be concluded that aeration time is a factor to improve the effectiveness of TCOD removals. In Phase 5, a one-day idle period introduced into the 4-days cycle: three days for aeration and one day for idle period. Sampling was conducted on the third day after the aeration and fourth day after the idle period. The TCOD removals on the third day after the aeration and fourth day after the idle period was found to be approximately $73 \%$ and $82 \%$, respectively. Phase 5 was also repeated and showed similar results. Phase 6 included a six-days cycle that consisted of six days aeration with a settling time of 60-75 minutes. Sampling was conducted at the end of the cycle and the percentage TCOD removal obtained was approximately $81 \%$.

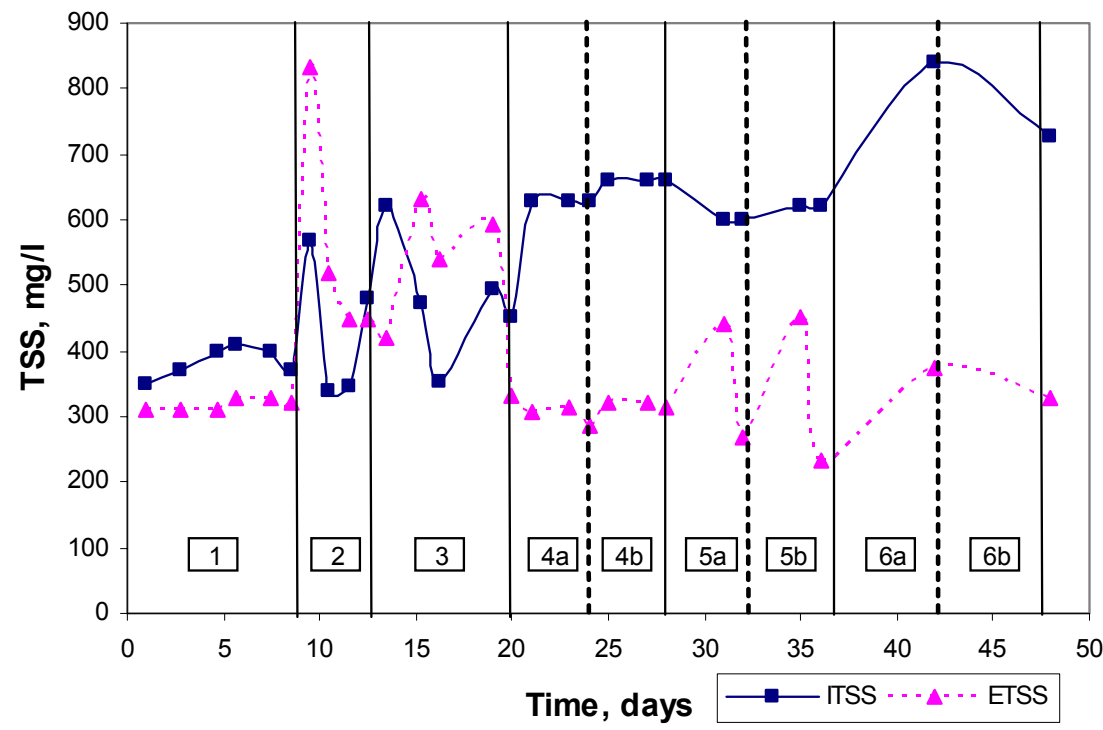

Figure 3: TSS versus time.

\subsection{Soluble COD results in SBR}

Figure 5 showed the influent soluble COD (ISCOD) and effluent soluble COD (ESCOD) throughout the study. The results achieved were almost the similar as in TCOD except that in most cases SCOD had a higher removal percentage compared to TCOD. This may be because the organic matter that was degraded by the bacteria was mainly in the soluble phase. In Phase 1, highest percentage SCOD removal was approximately $36 \%$ that was recorded on the fifth sampling point. The percentage SCOD removal in Phase 2 was approximately $34 \%$ removal of SCOD. However, when the settling period was increased to 60 
minutes for the $1^{\text {st }}$ and $5^{\text {th }}$ sampling points in Phase 3 the percentage SCOD removals increased to 53\%. In phase 4 , with a settling time of $60-75$ mins and a four days aeration period, the percentage SCOD removal achieved was $82 \%$. It was observed that, samplings on the first and third day resulted in percentage SCOD removals of $75 \%$ and $80 \%$, respectively. Similar removals were obtained when the phase was repeated in Phase $4 \mathrm{~b}$. It can be seen that there was not much difference between the percentage SCOD removals for the third and fourth day samplings. Hence, it can be concluded that a three days aeration period may be adequate. Phase 5 cycle included a three days aeration and one day idle time. The percentage SCOD removal was approximately $80 \%$ on the third sampling after aeration and $88 \%$ removal after idle time. The cycle was repeated in Phase $5 \mathrm{~b}$, which proved that idle time; increase the effectiveness of the treatment. To determine if a longer aeration time, more than four days would be more effective, Phase 6 was run with six days aeration. At the end of the cycle, the percentage SCOD removal was approximately $85 \%$. A repeat Phase $6 \mathrm{~b}$ gave similar removal results. However, it was observed that Phase 5 gave the best conditions for treating TSS and COD of POME using the SBR system.

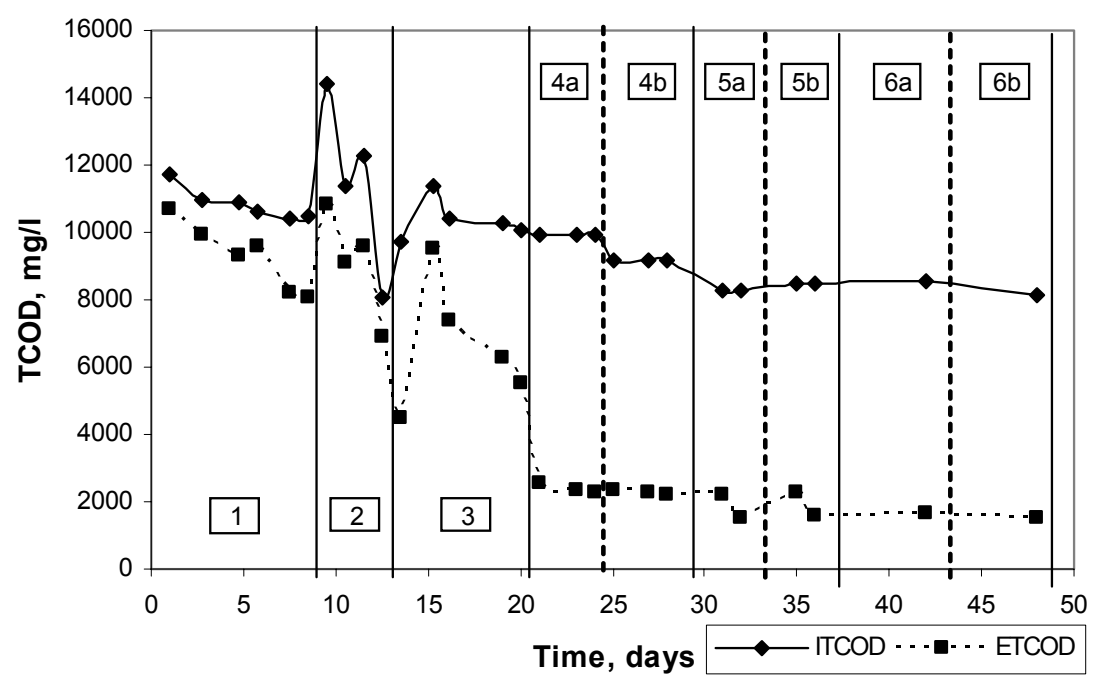

Figure 4: Total COD versus time.

\section{Conclusions}

For the SBR system studied, six different phases were conducted with varying parameters of concern. From the study, it can be concluded that Phase 5 with a four days cycle: three days for aeration and another day for idle period gave the best performance in removal of TSS and COD. The percentage removals of TSS, TCOD and SCOD for this phase were found to be approximately $62 \%, 82 \%$ and $88 \%$, respectively. The SBR system could be used by the mill's system by 
incorporating the system in its present aerobic-ponding treatment system. However, further research could be carried out to further investigate this potential.

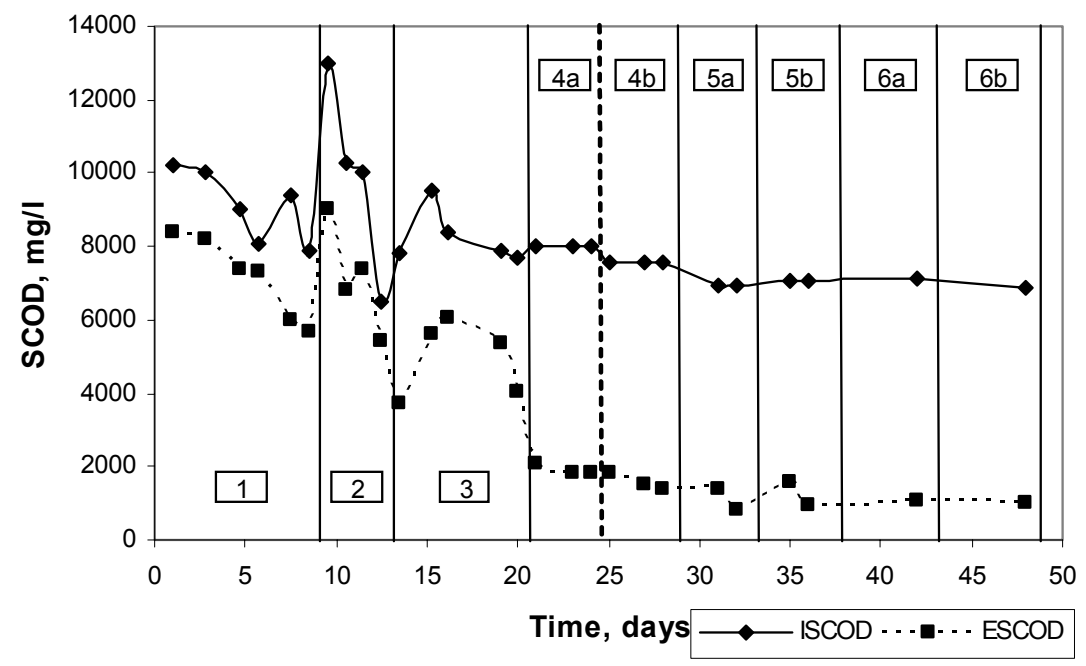

Figure 5: SCOD versus time.

\section{References}

[1] Zulkifli, I., Effluent related fee in the palm oil industry of Malaysia, United Nations ESCAP virtual conference, Department of Environment Malaysia, 1997.

[2] Khalid, A. R., Unilateral Environment Regulations and the Implications for International Commodity-Related Environment Agreement, Nautilus Institute Workshop on Trade and Environment in Asia-Pacific: Prospects for Regional Cooperation, 1994.

[3] Ahmad, AL, Sithamparam, K, Zulkali, MMD, and Ismail, S., Extraction of Residue Oil from Palm Oil Mill Effluent (POME) Using Organic Solvent, AJSTD Vol. 20 Issue 3\&4, pp. 385-394, 2003.

[4] GTZ, Environmental Management Guidelines for the Palm Oil Industry, PN 2000.2266.5-001.00, pp 41-47, 1997.

[5] Thanh, N. C, Palm Oil Wastewater Treatment Study in Malaysia and Thailand, Asian Institute of Technology, Report No. 114, 1980.

[6] Dae, S.L and Jong, M. P., Neural Network Modeling for On-line Estimation of Nutrient Dynamics in a Sequentially-operated Batch Reactor, School of Environmental Engineering, POSTECH, South Korea, 1999. 